Conclusions PR as currently delivered gives initial benefits to participants with ILD, however these are not sustained. More tailored approaches to this group are needed to improve the sustainability of response to PR.

\section{S100 IS IT FEASIBLE TO ASSESS DYNAMIC HYPERINFLATION DURING AN INCREMENTAL TREADMILL TEST IN PATIENTS WITH SEVERE ASTHMA?}

${ }^{1} \mathrm{~S}$ Majd, ${ }^{2} \mathrm{TE}$ Dolmage, ${ }^{3} \mathrm{RH}$ Green, ${ }^{1} \mathrm{P}$ Bradding, ${ }^{4} \mathrm{~S} J$ Singh, ${ }^{3} \mathrm{RA}$ Evans. 'Leicester Respiratory Biomedical Research Unit, University of Leicester, Leicester, UK; ${ }^{2}$ Respiratory Department, West Park Healthcare Centre, Toronto, Canada; ${ }^{3}$ Respiratory Department, Glenfield Hospital, Leicester, UK; ${ }^{4}$ Centre for Exercise Rehabilitation Science, GlenfieldHospital, Leicester, UK

\subsection{6/thoraxjnl-2015-207770.106}

Introduction We wish to investigate whether dynamic hyperinflation contributes to exercise intolerance in patients with severe asthma. It is unclear whether there is an influence by the exercise platform. To begin with, we explored whether performing serial inspiratory capacity (IC) manoeuvres is feasible during a maximal incremental treadmill test in patients with severe asthma.

Method Patients with severe asthma (step 4-5 of the British Thoracic Society guidelines), MRC dyspnoea grade $\geq 2$, were recruited from physicians specialising in the care of patients with difficult-to-treat asthma at Glenfield Hospital, Leicester. Patients were excluded if they had both fixed airflow obstruction $\left(\mathrm{FEV}_{1} /\right.$ FVC $<70 \%)$ and a smoking history of $\geq 10$ pack years. All participants performed an incremental treadmill test to intolerance, with expiratory gas analysis, designed to produce a linear increase in peak oxygen uptake $\left(\mathrm{VO}_{2}\right) \cdot{ }^{1}$ Patients performed a practice resting inspiratory capacity manoeuvre and then subsequently at rest, during the warm up phase and every two minutes during exercise.

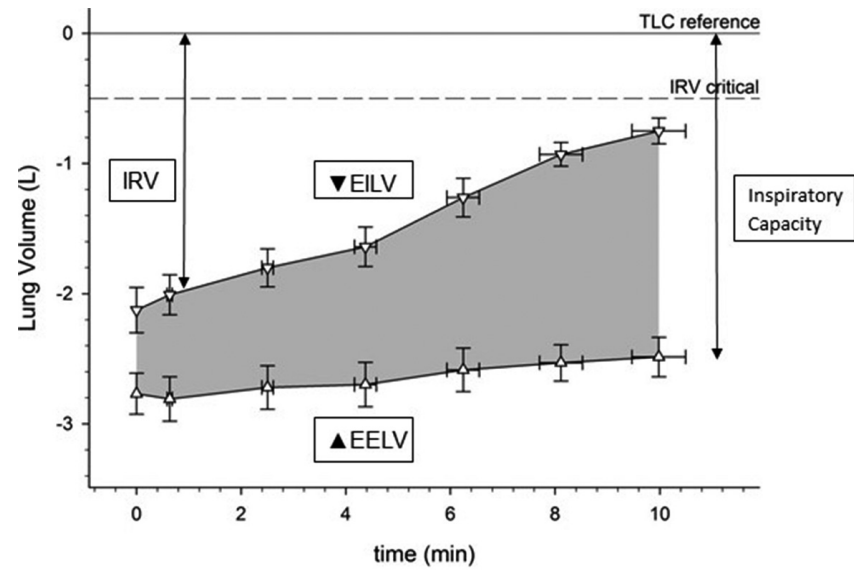

EELV: End Expiratory Lung Volume, EILV: End Inspiratory Lung Volume, IRV: Inspiratory Reserve Volume, TLC: Total Lung Capacity.

Abstract S100 Figure 1 Inspiratory capacity during a maximal incremental treatmill test in patients with severe asthma

Results 18 participants (8 female, mean [SD] 49 [14] yrs, BMI 31 [7] $\mathrm{kg} / \mathrm{m}^{2}, \mathrm{FEV}_{1} / \mathrm{FVC} 70[13] \%, 17 \%$ were ex-smokers) completed the treadmill test in a duration of 482 [120] s.
Observations at peak exercise were: $\mathrm{VO}_{2} 2.0$ [0.4] L/min $(100$ [25]\% predicted); ventilation 67 [18] L/min (87 [20]\% maximum voluntary ventilation); heart rate 145 [17] beats/min (85 [9]\% predicted); Borg Score for breathlessness 7 [2], perceived exertion 17 [3], 16 were predominantly limited by breathlessness. 115 IC manoeuvres were performed with only one datapoint missed due to an incomplete manoeuvre. Figure 1 shows the mean end expiratory and inspiratory lung volumes during exercise. Six patients had an inspiratory reserve volume of $<500$ mls.

Conclusion Assessment for dynamic hyperinflation with serial inspiratory capacity manoeuvres during a maximal incremental treadmill test is feasible in patients with severe asthma. The relationship among lung volumes, time and ventilation can be established from rest to peak exercise with minimal practice of the IC manoeuvre or interruption to the test in this patient population.

\section{REFERENCE}

1 Porszasz J, Casaburi R, Somfay A, et al. Med Sci Sports Exerc. 2003;35: 1596-1603

\section{S101 DO THOSE PATIENTS WITH A CHRONIC RESPIRATORY DISEASE THAT WALK AT A FASTER WALKING SPEED IMPROVE MORE POST PULMONARY REHABILITATION?}

${ }^{1}$ EJL Chaplin, ${ }^{1} \mathrm{~S}$ Lohar, ${ }^{1} \mathrm{~S} J$ Singh, ${ }^{2} \mathrm{~S} J$ Singh. ${ }^{1}$ Centre for Exercise and Rehabilitation Science, Pulmonary Rehabilitation Department, Glenfield Hospital, University Hospitals of Leicester, Leicester, UK; ${ }^{2}$ School of Sport, Exercise and Health Sciences, Loughborough University, Loughborough, UK

\subsection{6/thoraxjnl-2015-207770.107}

Introduction Several baseline factors influence the response to Pulmonary Rehabilitation (PR). The Incremental and Endurance shuttle walk test is used to prescribe an exercise walking speed for patients with a chronic respiratory disease as part of a PR programme. We wished to explore the speed and duration of baseline endurance performance and observe how this impacted upon changes post rehabilitation particularly around the higher speeds of the endurance shuttle walk test (ESWT).

Methods Patients completed a 7 week outpatient PR programme comprising of both endurance and strength training. The endurance training is based on the ESWT speed which is $85 \%$ of the individual maximal capacity derived from the incremental shuttle walk test (ISWT). The ISWT and subsequent ESWT were performed at baseline and discharge. Patients were categorised into low $(<3.6 \mathrm{~km} / \mathrm{hr})$ or high $(>3.6 \mathrm{~km} / \mathrm{hr})$ speed walkers based on their baseline ESWT performance.

Results 990 patients completed the SWT: 567 low speed walkers (mean age $70.9 \pm 9.7$ years; $\mathrm{FEV}_{1} 1.5 \mathrm{~L} \pm 4.9$; BMI $27.6 \pm$ $9.0 \mathrm{~kg} / \mathrm{m}^{2}$; MRC 4 (IQR 3-4); ISWT pre $128.4 \pm 61.6 \mathrm{~m}$; ESWT pre $166.3 \pm 161.5$ secs) and 423 high speed walkers (mean age $67.8 \pm 9.2$ years; $\mathrm{FEV}_{1} 1.62 \mathrm{~L} \pm 3.8$; BMI $27.1 \pm$ $14.0 \mathrm{~kg} / \mathrm{m}^{2}$; MRC 3(IQR 2-3); ISWT pre $373.4 \pm 103.3 \mathrm{~m}$; ESWT pre $262.4 \pm 147.6$ secs). Those walking at a higher speed had a significantly higher pre ESWT ( $\mathrm{p} \leq 0.001)$. A statistically significant improvement was observed in the ESWT within each group (low: mean change $344.2 \pm 401.5 \mathrm{p} \leq 0.001$; high: mean change 369.3 secs $p \leq 0.001)$. However the change in ESWT was not significantly different between the groups $(p=0.3)$. 